\title{
PRÁTICAS, REPRESENTAÇÕES E MEDIAÇÃO: O USO DOS LAPTOPS EDUCACIONAIS E AS INTERVENÇÕES DOCENTES NO PROCESSO DE APRENDIZAGEM DÁ EDUCAÇÃO BÁSICA
}

\author{
PRÁCTICAS, REPRESENTACIONES Y MEDIACIÓN: EL USO DE LOS \\ LAPTOPS EDUCACIONALES Y LAS INTERVENCIONES DOCENTES EN EL \\ PROCESO DE APRENDIZAJE DE LA EDUCACIÓN BÁSICA
}

\author{
PRACTICES, REPRESENTATIONS AND MEDIATION: THE USE OF \\ EDUCATIVE LAPTOPS AND TEACHERS' INTERVENTIONS IN THE PROCESS \\ OF LEARNING IN BASIC EDUCATION
}

\author{
Eliana Maria do Sacramento SOARES ${ }^{1}$ \\ Elaine Cátia Falcade MASCHIO ${ }^{2}$
}

RESUMO: O objetivo deste estudo é analisar o entendimento dos professores sobre o uso de Laptops Educacionais no processo de ensino aprendizagem da Educação Básica e refletir acerca da mediação pedagógica, que pode ser realizada a partir do uso desses recursos, com potencial para levar o aluno a desencadear processos internos de significação. Para isso tomamos os conceitos de representação, cunhado por Chartier, de prática educativa, conforme propõe Zabala, e de aprendizagem e mediação a partir da teoria vygotskiana. Para alcançar tal finalidade, foi constituído um corpus de pesquisa, com a colaboração de cinco professores que atuam no Ensino Fundamental em uma escola municipal do interior gaúcho. A metodologia elegida foi de abordagem qualitativa, permitindo o envolvimento ativo dos pesquisadores por meio da realização de um grupo focal, que gerou um rico conjunto de registros escritos revelando a subjetividade dos sujeitos colaboradores da pesquisa. Os resultados, baseados na análise textual discursiva, mostram que a presença dos laptops educacionais tornam as aulas mais dinâmicas e possibilitam uma reorganização das tarefas escolares, em termos de tempo e espaço. Revelam também um fortalecimento na interação professor-aluno. As verbalizações dos professores permitem inferir sobre a necessidade deles ampliarem a reflexão sobre o potencial desses recursos, por meio de encontros de estudos com seus pares, a fim de implementarem suas práticas com intervenções mediadoras que possibilitem aos alunos desenvolverem processos internos de significação, de forma que as tarefas realizadas, com auxílio dos recursos digitais, possam funcionar como ação mediadora da aprendizagem, como propõe a teoria vygotskiana.

PALAVRAS-CHAVE: Práticas pedagógicas. Tecnologias digitais. Mediação. Aprendizagem.

\footnotetext{
${ }^{1}$ Universidade de Caxias do Sul, RS - Brasil. Pesquisadora e professora do Centro de Ciências Exatas e da Tecnologia e do Programa de Pós-graduação, Mestrado e Doutorado em Educação E-mail: emsoares@ucs.br.

${ }^{2}$ Universidade de Caxias do Sul, RS - Brasil. Realiza estágio de Pós-Doutorado no Programa de PósGraduação, Mestrado e Doutorado em Educação da Universidade de Caxias do Sul, RS - Brasil. E-mail: elainefalcade@uol.com.br.
} 
RESUMEN: El objetivo de este estudio es analizar el entendimiento de los profesores sobre el uso de Laptops Educacionales en el proceso de enseñanza aprendizaje de la Educación Básica y reflexionar acerca de la mediación pedagógica, que puede ser realizada a partir del uso de esos recursos, con potencial para llevar al alumno a desencadenar procesos internos de significación. Para eso, tomamos los conceptos de representación, presentados por Chartier, de práctica educativa como lo propone Zabala y de aprendizaje y mediación a partir de la teoría vygotskiana. Para alcanzar tal finalidad, fue constituido un corpus de investigación, con la colaboración de cinco profesores que actúan en la Enseñanza Fundamental en una escuela municipal del interior de Rio Grande do Sul. La metodología elegida fue de abordaje cualitativo, permitiendo el envolvimiento activo de los investigadores por medio de la realización de un grupo focal, que generó un rico conjunto de registros escritos revelando la subjetividad de los sujetos colaboradores de la investigación. Los resultados, basados en el análisis textual discursivo, muestran que la presencia de los laptops educacionales hace que las clases sean más dinámicas y posibilitan una reorganización de las tareas escolares, en términos de tempo y espacio. Revelan, también, un fortalecimiento en la interacción profesor-alumno. Las verbalizaciones de los profesores permiten inferir sobre la necesidad de que amplien la reflexión sobre el potencial de esos recursos, por medio de encuentros de estudios con sus pares, a fin de implementar sus prácticas con intervenciones mediadoras que posibiliten a los alumnos, desarrollar procesos internos de significación, de forma que las tareas realizadas, con auxilio de los recursos digitales, puedan funcionar como acción mediadora del aprendizaje, como lo propone la teoría vygotskiana.

PALAVRAS CLAVE: Prácticas pedagógicas. Tecnologías digitales. Mediación. Aprendizaje.

ABSTRACT: The aim of this study is to analyze teachers' understanding about the use of Educative Laptops in the process of teaching and learning in Basic Education, as well as to reflect about pedagogic mediation that can be done from the use of these resources, with potential to take the student to trigger internal processes of meaning. For this, we take the concepts of representation, presented by Chartier, those of education practice, as Zabala proposes it, and those of learning and mediation from Vygotski's theory. To achieve this aim, a corpus for investigation was constituted, with collaboration of five teachers who work in Basic Teaching at a municipal school in the countryside of Rio Grande do Sul. The methodology chosen was of qualitative approach, allowing the active involvement of researchers through a focal group, which generated a rich set of written reports, which reveal the subjectivity of the collaborating subjects of this research. Results based on discourse textual analysis, show that the presence of education laptops makes classes more dynamic and allows a reorganization of school tasks, in terms of time and space. They also reveal a reinforcement in the teacher-student interaction. Teachers' verbalizations allow to infer the need of making reflection about these resources wider, through study meetings with their pairs, to implement their practices with mediating interventions. These would allow students to develop internal processes of meaning, so the tasks done, with the aid of digital resources, can work as a mediating action in learning, as Vygotski's theory puts it.

KEYWORDS: Pedagogical practices. Digital technologies. Mediation. Learning. 


\section{Introdução}

O presente estudo tem como objetivo analisar a compreensão e as práticas dos professores no uso dos Laptops Educacionais. Considerando a atuação desse docente no processo de ensino na Educação Básica, a partir de suas verbalizações, pretende-se propor uma reflexão sobre o papel da mediação na organização das práticas de aprendizagem. Desse modo, entendemos que as práticas mediadoras tem potencial para desencadear nos alunos processos internos de significação, de maneira que a ação realizada, com auxílio desses recursos digitais, possa funcionar como ação mediadora da aprendizagem, como propõe a teoria vygotskiana. Diante disso, desloca-se o foco da tecnologia em si mesma, no processo de ensino aprendizagem, para se localizar nas relações que podem ser estabelecidas entre ela e as práticas pedagógicas realizadas por seu intermédio.

Para entender como os professores representam a inserção de tecnologias digitais em seu espaço escolar, no contexto deste estudo, laptops na modalidade 1-1, como ponto de partida para o diálogo sobre a necessidade de mediar as práticas educativas no uso das tecnologias digitais, realizamos um estudo tendo como objeto de pesquisa um corpus constituído por dados gerados por meio de uma entrevista com grupo focal numa escola municipal, com inserção de laptops na modalidade 1-1, do programa UCA, no Rio Grande do Sul.

O programa PROUCA - Um Computador por Aluno foi uma iniciativa do Programa Nacional de Informática na Educação (Proinfo), que tinha como propósito desencadear um processo de inclusão digital mediante a aquisição e a distribuição de computadores portáteis em escolas públicas. A modalidade ou modelo 1-1, possibilitada pelo programa, (Disponível em: <http://www.fnde.gov.br/programas/programanacional-de-tecnologia-educacional-proinfo/proinfo-projeto-um-computador-por-alunouca >.), diz respeito à forma como cada aluno pode acessar seu laptop em sala de aula para as práticas de aprendizagem. Nesse caso, cada um tem seu laptop para as práticas propostas, diferente de situações nas quais eles se dirigem a um laboratório de informática, onde alguns usam um mesmo computador, ou quando o professor usa um computador ligado a um projetor para mostrar a tela aos estudantes. Assim, os alunos podem ter acesso simultâneo a informações, podem comunicar-se em rede e utilizar os recursos computacionais disponíveis. Nesse contexto podem surgir novas possibilidades para as práticas pedagógicas e para a construção da aprendizagem, ao mesmo tempo em 
que surgem novas demandas para os professores em termos de saberes, planejamento e organização da aula.

Escolhemos entrevistas em grupos focais para constituir o corpus. Esse delineamento metodológico permite reunir num mesmo local sujeitos que, por meio do diálogo, relatam informações acerca de um tema específico (NETO, MOREIRA \& SUCENA, 2002). Dessa forma, com a intencionalidade focada no entendimento de como os professores perceberam e deram sentido à inserção de laptops, na modalidade 1-1, em sua escola, desenvolvemos uma conversa tendo como tema aquilo que mudou e o que permaneceu, a partir da inserção dos laptops, na modalidade 1-1, conforme proposto pelo programa UCA. Mais especificamente, os participantes foram convidados a falar da organização da aula, da relação professor-aluno, das tarefas relacionadas às práticas docentes, no sentido de rupturas e permanências percebidas. Foram convidados cinco professores que estão utilizando os laptops em seu cotidiano, que se reuniram em setembro de 2016 junto com a pesquisadora, numa sala na escola municipal onde atuam, a seu convite e com a autorização da direção da escola. As vozes dos professores foram representadas pela identificação alfabética: Professor A, B, C, D e E. Quanto ao perfil dos professores participantes da pesquisa, foi possível verificar que se tratavam de profissionais licenciados: o Professor A, formado em Língua Inglesa, atua nas 6a, 8a, 9a séries, usa laptop toda semana a 2 anos; o Professor $\mathrm{B}$, formado em Ciências e Matemática, atua nas 7a, 8a, 9a séries, usa o laptop a 2 anos; o Professor C, formado em Ciências Humanas, usa a 3 anos; o Professor D, com formação em Artes, ministra aulas nas 6a, 9a séries, e utiliza semanalmente a 6 anos; o Professor E, que é formado em História e Geografia, também atua como coordenador pedagógico, declarou que utiliza a tecnologia há mais de 2 anos.

Cumpre ressaltar que os professores depoentes foram relatando suas ideias e a pesquisadora foi incentivando, pedindo para ilustrar, dar exemplos e comentar. Assim a conversa foi mediada pela pesquisadora, que teve a função de intermediar as interlocuções entre os professores que participaram. Essa mediação foi imbuída de sensibilidade na escuta, sem julgamentos, com aceitação e atenta para que pudesse deixar que as falas surgissem e pudessem revelar as percepções e sentidos dados pelos participantes acerca do tema em estudo. Isso é consoante com Barbier (2002), quando esse autor se refere ao formato desse tipo de abordagem para gerar dados, numa pesquisa científica. 
As conversações do grupo focal foram registradas por meio de gravação, com consentimento dos participantes, que também assinaram termo de consentimento esclarecido. Finalizando a conversação desenvolvida, no grupo focal, cada participante teve oportunidade de expressar-se de forma livre e de avaliar ou comentar a atividade desenvolvida. Realizado o grupo focal, o conteúdo do mesmo foi ouvido e transcrito na busca de entender o sentido dado pelos professores, sobre as mudanças e permanências na escola, em sua convivência diária utilizando os laptops.

Os dados foram transcritos para compor o corpus que foi tratado segundo a análise textual discursiva proposta por Moraes e Galiazzi (2007). Assim, em movimentos de ida e vinda do corpus, tendo a teoria como norteadora e o tema da pesquisa como fio condutor, foram realizados movimentos de unitarização e de categorização, que culminaram com a identificação de categorias emergentes, na busca de entender a dinâmica relacional dos professores em sua convivência diária, apreendidas pelos seus registros no grupo focal.

Mais especificamente, o corpus foi analisado a partir do conceito de representação, cunhado por Chartier (1990), e de prática educativa, conforme propõe Zabala (1998). Os conceitos de mediação e de internalização da visão vygotskiana também estiveram presentes, a fim de entender como os elementos externos, advindos do uso dos laptops, podiam funcionar como potencializadores de representações mentais relacionadas à internalização. Assim, identificamos e articulamos categorias emergentes, a partir das contribuições dos professores, no grupo focal, a fim de construir um entendimento acerca da representação que eles realizaram sobre sua prática, no contexto de inserção dos laptops, considerando continuidades e rupturas; além de entender como essas práticas poderiam ser implementadas no sentido de possibilitar movimentos de significação e de aprendizagem. Isso foi realizado, uma vez que o conceito de representação para Chartier (1990) potencializa a compreensão sobre a realidade social e cultural. Embora em perspectiva histórica, sua contribuição auxilia no entendimento de que as percepções dos sujeitos, representadas na construção de imagens do presente, são construídas por meio das práticas culturais.

Poderíamos olhar para as representações na perspectiva de autores que tenham contribuído para a discussão de representação social. Como, por exemplo, os estudos feitos pelo psicólogo social francês Serge Moscovici (1978), superando a perspectiva individualista da Psicologia, pautando sua produção na ideia de que a representação é um produto ao mesmo tempo individual ou coletivo, sendo, então, um processo que 
possibilita a reconstrução do real, dos sujeitos em relação com os objetos e o seu contexto.

Mas a opção pelo conceito de representação em Roger Chartier advém da articulação entre representação e práticas culturais. Neste caso, a prática pedagógica ou escolar - a qual se configura como objeto desta pesquisa - é concebida como uma prática cultural, uma vez que o processo de escolarização é um fenômeno cultural. Para tanto, a representação abrange o imaginário social dos sujeitos, os modos como eles representam o real e como, por meio de práticas de produção de sentido, constroem uma determinada realidade social, pensada e dada a ler (CHARTIER, 1990).

Sob essa abordagem, buscamos inferir de que maneira os professores da Educação Básica representam seu cotidiano da sala de aula, a partir da inserção de laptops na modalidade 1-1, e como impõem ou não suas percepções na materialização de suas práticas pedagógicas nesse cenário modificado. Para Antony Zabala (1998), a prática pedagógica possui muitas variáveis, portanto, diz respeito a uma estrutura complexa que engloba desde os parâmetros institucionais até as possibilidades reais dos professores de intervenção. Assim, a prática pedagógica é antes uma ação reflexiva, que não se reduz ao momento em que são produzidos os processos educativos da aula.

Conforme Zabala (1998, p. 23), a prática:

[...] não é o resultado de uma decisão firme sobre as finalidades do ensino e segundo uma concepção determinada dos processos de ensino/aprendizagem, mas corresponde àquilo que pode se fazer levando em conta a globalidade do contexto educacional em que se desenvolve a prática educativa.

Sob essa abordagem, a prática pedagógica que se efetiva no cotidiano da sala de aula não é fruto de uma imposição unilateral e unidimensional. Ela é lugar de produção de conhecimento conectando elementos mais amplos, sejam eles internos e externos a esse contexto.

A prática pedagógica, no contexto deste estudo, está sendo modificada pela presença de tecnologia educacional digital. Sendo assim, nosso propósito nesta investigação é entender as modificações e aquilo que a presença da tecnologia digital provoca nesse contexto. Para isso tomaremos o sentido daquilo que os professores, a partir de múltiplos fatores, valores e condições, atribuem à sua prática pedagógica. Como elas estão sendo inseridas, que lacunas e ausências estão sendo geradas, como estão sendo capazes ou não de transformar suas práticas. 
Essas possibilidades de investigação são evidenciadas pelas representações dos sujeitos, que colocam o pesquisador em contato com a realidade construída no cotidiano da escolarização no uso de tecnologias digitais, e possibilitam pensar estratégias de mudança, tendo como lócus o fazer docente.

Ademais, as estratégias de mudança são propostas na parte final deste texto. Baseada no conceito de mediação da teoria vygotskiana, propõe-se uma reflexão sobre a necessidade do professor implementar sua prática, atuando a partir de intervenções mediadoras com potencial de desencadear nos alunos processos de internalização: orientando, desafiando e problematizando, de forma a articular o uso dos recursos digitais em suas práticas pedagógicas. Ou seja, as atividades realizadas com a presença de tecnologia digital, articuladas com intervenções problematizadoras e instigadoras, podem levar o aluno a realizar movimentos de internalização, possibilitando que a aprendizagem aconteça. Nessa perspectiva, o uso dos recursos digitais, articulados a intervenções e ações do professor, pode levar o aluno a refletir sobre a ação realizada por intermédio do laptop, em busca de compreendê-la, resultando em práticas interativas precursoras da aprendizagem e de seu desenvolvimento.

Importante ressaltar que a presente pesquisa se insere no rol das investigações que têm ganhado atenção nas últimas décadas no campo da educação, uma vez que estamos imersos num cenário social permeado pelas tecnologias digitais. Assim, vários estudos buscam entender como o cenário escolar está lidando com a inserção digital, colocando em debate os limites e as possibilidades do uso das tecnologias digitais no cotidiano da escola. Valentini, Pescador e Soares (2013), analisando a inserção de laptops na modalidade 1-1, argumentam que projetos como o UCA favorecem o surgimento de diferentes formas de organizar a aula, constituindo-se numa oportunidade para que as práticas educativas sejam redimensionadas.

Outros estudos alertam que a presença das tecnologias digitais nas práticas tem levado à pseudo inovações, uma vez que realizam a inserção desses artefatos apenas para suportar ou modernizar práticas pedagógicas tradicionais (FAGUNDES, L. C.; VALENTINI, C. B.; SOARES, E. M. S., 2010; LOPES, D. Q.; VALENTINI, C. B., 2012). Eles reiteram a necessidade de novas perspectivas para as práticas pedagógicas no contexto digital, em especial no que diz respeito ao redimensionamento e à ressignificação.

Renovar a prática pedagógica tem sido desafiador e perturbador, como destacam Fagundes, Valentini e Soares (2010). Elas argumentam que professores e alunos têm um 
novo elemento no cenário que traz demandas e muitas possibilidades, e sendo assim pode ser catalisador de mudanças nas práticas docentes e na cultura escolar vigentes, desde que esses atores do processo repensem todo o processo educativo, incluindo novas formas de organizar as tarefas e as interações.

Valentini, Pescador e Soares (2013) ressaltam que a inserção dos laptops, no projeto UCA, em uma escola municipal, provocou a reconfiguração da sala de aula, em algumas situações, e a emergência de novas configurações de relações interpessoais entre estudantes e professores. Indicam, ainda, que o processo pedagógico está saindo, em alguns momentos, do foco do discurso do professor, abrindo novas possibilidades de interação em rede, onde estudantes e professores participam mais ativamente do processo educativo, atuando em convivência. As autoras relatam ainda algum tensionamento entre os domínios de ação do professor e do aluno, uma vez que o professor em alguns casos tem dificuldade de sair de seu papel de controle, diante de estudantes que estão se constituindo em movimentos de exploração, questionamentos e interação.

\section{O que os professores pensam sobre a inserção dos laptops na sua prática}

Entendendo a prática na perspectiva de Zabala (1998), ou seja, como uma ação reflexiva, um processo que envolve um conjunto de variáveis que incidem diretamente sobre esse processo, destacamos aqui a representação dos professores compreendendo-a como um dos elementos desse conjunto de variáveis que constituem a prática pedagógica. Ele não é o determinante, mas é fruto das relações subjetivas e contextuais nas quais o docente está inserido.

Por esse viés, buscamos entender o sentido que os professores deram para suas práticas pedagógicas, atuando em seu cotidiano e tendo em vista seu entendimento como sujeito envolvido num cenário de inserção digital, que o desafia a incluir o laptop em sua atuação. Sentido esse construído tendo como base seus valores, saberes e condições. Dessa maneira, o processo de unitarização e categorização do corpus empírico resultou em três categorias emergentes: a forma complementar como professores utilizam os laptop; as mudanças sentidas na prática pedagógica a partir do uso dos laptops; e, os desafios futuros considerando as possibilidades do laptop como 
elemento mediador da aprendizagem, indo além da simples fonte de informação ou de complementação das práticas já estabelecidas no processo de escolarização.

Os professores relataram que quando os laptops foram inseridos no contexto da escola, foram realizadas oficinas de formação para que eles aprendessem a explorar o recurso, e entender o seu funcionamento. Comentaram que o sistema operacional foi modificado, logo no início do processo, sendo substituído por um mais amigável. Eles relatam também que alguns equipamentos já não funcionam bem, outros estão com as baterias danificadas, dificultando o uso. Relataram ainda alguns problemas relacionados à infraestrutura de uso, falta de extensões e cabos. Uma vez que os equipamentos ficam guardados em armários, eles comentam que retirá-los dos armários e instalar tudo demanda tempo, e às vezes isso é fator da não utilização.

\section{Complementaridade das práticas: o laptop como extensão do quadro, do livro e do caderno}

Essa categoria emergente colocou em evidência a representação dos professores sobre o uso dos laptops como complementar às práticas pedagógicas já estabelecidas. Portanto, diz respeito a usos e apropriações dessa tecnologia, como, por exemplo: o uso do editor de texto do laptop para registrar as notas de aula, de forma que o aluno usa a interface da tela, como a folha do caderno, digitando o que antes ele escrevia. De forma similar, o professor,ao invés de escrever no quadro informações acerca do conteúdo, ou de pedir para o aluno consultar o livro, agora pede que faça buscas na Internet.

Algumas das verbalizações ilustram essa relação, colocando em evidência a complementaridade das práticas. A tarefa de realizar pesquisa escolar, no sentido de buscar informações acerca de um tema, que antes acontecia principalmente nos livros e pela exposição do professor, agora ocorre por meio da consulta à internet, complementando o ato já consolidado da cultura escolar que é a pesquisa.

[...] ao invés de colocar conteúdo no quadro, os alunos podiam acessar por meio da rede. Mudou a autonomia do aluno, dele poder pesquisar sozinho, não fica esperando que eu colocasse no quadro. A gente trabalhava com a tabela (se referindo a tabela periódica, para aulas de química) e depois ia para internet, para ver como era. Acho que o uso do recurso é bom, pois no livro não tem tudo, na internet a gente pode ampliar, tem mais coisas. (Prof B) 
Percebe-se que os laptops são integrados às práticas da aula como recursos que complementam as atividades tradicionalmente desenvolvidas, como práticas pedagógicas: cópia de textos, reprodução de imagens e vídeos, pesquisa no dicionário.

Tais representações são evidenciadas nas falas abaixo:

Eu uso muito a rede, a internet, sou professor de inglês e isso ajuda muito, por exemplo, o dicionário. É bem mais fácil de procurar. Uso também o tradutor. Isso ajuda bastante. (prof A).

Antes eu passava o conteúdo no quadro, agora eles podem buscar na internet. Fiquei perdida, pois antes eu dava no quadro, agora o lap podia oferecer. Assim, o lap complementava o que tinha no livro. (prof B).

Eu uso as imagens, antes eu trazia imagens xerografadas para as aulas, com o recurso eles podiam "pegar direto". Eu fazia uma seleção das imagens. A gente podia também viajar pelos museus, mais possibilidades. (prof D).

Uso mesmo para fazer pesquisa, porque no livro não tem tudo. (prof C).

Cumpre notar, como afirma Mill (2013),que a substituição de uma tecnologia simples por outra mais moderna pode não significar mudança das práticas, uma vez que não diz respeito ao aprimoramento do processo de aprendizagem dos alunos. $\mathrm{O}$ exemplo abaixo ilustra essa afirmação, quanto da utilização dos jornais. Há tempos a escola reconhece o trabalho com os jornais no cotidiano da escola como recurso metodológico para a compreensão dos textos de linguagem jornalística. A inserção dos laptops não desconstrói nem modifica o potencial pedagógico dessa fonte escrita, mas amplia a possibilidade do seu acesso e manuseio.

$\mathrm{Na}$ internet tem de legal que as imagens são mais legais ampliam enormemente (se referindo ao zoom e a dinamicidade das imagens). Nós tínhamos leitura, e naquela época nós tínhamos que ler algo e eu comecei a pegar o lap para ler jornais do mundo. Lendo jornais de outros países, tem a versão traduzida. Bem legal. Eu pedia para eles procurarem o que esses jornais estão falando do brasil. (prof E).

Assim, essa categoria diz respeito às mudanças relatadas pelos professores relacionadas à maneira como os alunos acessam as informações e registram os conteúdos estudados. O laptop oferece um suporte diferente do que existia antes: livros e cadernos, que agora se transformam em sites de busca e telas com softwares de textos. 


\section{O sentido das mudanças na prática pedagógica no cotidiano escolar após o uso dos laptops}

Essa categoria emergente está relacionada às mudanças no cotidiano escolar, com a inserção digital, em termos da reorganização da aula, em termos de tempo e de espaço. Também incluem mudanças na forma dos alunos atuarem em sala de aula. Não há dúvidas que a disposição material e espacial que a inserção dos laptops na modalidade 1.1 provoca no cotidiano escolar tem modificado a prática pedagógica. Uma dessas mudanças tem se concentrado na reordenação do tempo escolar. Conforme Maschio e Martins (2014), o computador inserido no contexto das atividades diárias da sala de aula otimiza o tempo da aula, ao passo que nos laboratórios de informática exige-se do professor a separação de parte do tempo do planejamento e o deslocamento dos sujeitos para outro espaço.

Outra transformação da aula diz respeito à forma como os professores percebem a motivação dos alunos na ação de explorar a receber as orientações docentes. Analogamente, os professores relataram que os laptops possibilitaram o fortalecimento da interação professor/aluno. Eles também observaram a ampliação de trabalhos coletivos, gerando uma maior participação dos alunos em cooperação.

Mudou muito pros alunos, mas mudou muito em mim. Quando os lap
chegaram a gente abriu as caixas e veio manual. Daí a gente tinha a
lógica: ver os manuais para ver como era e daí utilizar. Assim a gente
quando foi mostrar para os alunos, fez instruções, com cartazes para
eles aprenderem como usar, por exemplo, a gente fez cartaz dizendo o
que cada tecla funcionava, coisas assim. Fiz isso porque era nossa
lógica, dos professores, a minha (como coordenadora pedagógica).
Mas os alunos queriam era mexer e explorar, e isso eu fui aprendendo
com eles. (o aspecto de como funcionava cada tecla, cada coisa. Fui
aprendendo muito com eles isso. Outro ponto que me marcou muito
foi ver que alguns alunos que eram péssimos no caderno, que não
fazia coisas, foi excelente, fazia trabalhos muito bom com o lap (prof
E).

Cotejando as representações dos sujeitos, observa-se que a simples introdução dos laptops reconfigurou a lógica estática da aula, revelando que a motivação em explorar aquele objeto poderia proporcionar uma atividade atrativa, dinâmica e lúdica. Assim, muitos foram os sentidos e significados atribuídos pelos docentes, desencadeando uma mudança na relação professor, objeto do conhecimento e 
aluno, e colocando em evidência a importância da materialidade neste processo de ensino e aprendizagem.

No entanto, ainda há muitas possibilidades de transformação da prática, sendo factível a reflexão sobre os desafios futuros da escola quanto ao uso dos dispositivos digitais. Para isso é preciso ir além da instrumentalização das tecnologias, é preciso despertar a consciência por meio da reflexão programada a partir e sobre a prática pedagógica. Isso deve ocorrer nos processos de formação docente inicial, continuada e no cotidiano da escola.

\section{Os desafios futuros considerando as possibilidades do laptop}

Essa categoria está relacionada a verbalizações apresentadas pelos professores que mostram que eles estão refletindo sobre o que acontece, buscando entender como o laptop está atuando no processo de aprendizagem. O relato do prof A permite fazer essa inferência:

\footnotetext{
Numa aula, tive uma situação onde quatro alunas não entendiam algo que eu estava explicando. Aí eu propus que elas fossem pesquisar no lap, para ver se elas entendiam, sei lá; percebi que com isso elas entenderam; não sei o que aconteceu mas ...eu pedi para pesquisar e copiar no caderno o que elas encontraram, fazer o registro, né? Para não pegar o lap e ficar fazendo qualquer coisa.
}

Parece que as alunas ao buscar no laptop as informações e interagirem sobre o objeto de conhecimento, foram construindo algumas relações que propiciaram o entendimento do conceito. $\mathrm{O}$ fato de registrar, atuando sobre o objeto de conhecimento, algo que precisaria ser explorado, melhor estudado pelos professores, em seminários, para que eles pudessem entender as possibilidades de mediação do laptop, aliado a uma intervenção sua. Eles parecem intuir sobre isso. A verbalização do prof D sugere isso: "acho que ao copiar outras explicações, elas entenderam". O prof D ainda comenta: "Parece que foi mais uma mudança comportamental delas, assim... eu acho que isso facilitou que elas ficassem mais centradas". 


\section{Ressignificando as práticas tendo como base a reflexão sobre o fazer}

A análise realizada tendo como base a articulação entre as categorias emergentes identificadas indicam que eles estão refletindo sobre o que está acontecendo em suas práticas, permeadas pela presença do laptop e percebendo que é preciso mais do que simplesmente usar o recurso. Eles estão testando, incluindo as operacionalidades oferecidas pelo laptop em suas práticas e vendo o que acontece. Assim, as representações construídas pelos professores, quando analisadas por eles, parecem estar auxiliando-os e motivando-os a ir além do que estão realizando, para que a inserção dos laptops possa ser mais efetiva em seu cotidiano. Efetiva para potencializar o processo de aprendizagem.

Algumas de suas verbalizações revelam que eles já estão refletindo sobre suas práticas e sentem desejo de usar novos recursos, de entender algumas situações onde a exploração de possibilidades oferecidas pelo laptop parece auxiliar na aprendizagem. Isso sugere movimentos de reflexão e de análise crítica sobre a prática que estão desenvolvendo. Valentini, Pescador e Soares (2013) salientam a importância da apropriação das tecnologias digitais pelo professor e pelo aluno, para que elas sejam inseridas nas práticas, potencializando o processo de ensino aprendizagem, enfatizando a importância de reflexões e de análise crítica para que haja redimensionamento das práticas vigentes. Essas autoras argumentam que a reflexão sobre a prática de forma crítica e em parceria, pode ser um caminho para redimensionar a forma de pensar e criar novos caminhos para a conduta docente, no contexto digital. O que elas sinalizam está em consonância com o que pode ser inferido das verbalizações dos professores.

Sob essa abordagem, tudo indica que os professores estão percebendo a importância de participarem de seminários e vivências, interagindo com seus pares, onde as reflexões e análises acerca das práticas desenvolvidas possam ser sistematizadas e redimensionadas a partir de conceitos teóricos.

Moraes, Laurino e Machado (2013), realizando estudos acerca da formação docente para realizar suas práticas no contexto da inserção digital, recomenda que as ações de capacitação e formação precisam estar alicerçadas em reflexão e discussão, acerca da sua atuação, ou seja, observando e analisando sua ação cotidiana na escola. Essas autoras destacam que dessa forma eles podem ir construindo novas formas de conduzir sua prática e ressignificar suas ações. Concordamos com elas entendendo que a prática inovadora do professor acontecerá como resultado de processo de reflexão e 
observação da prática, articulada com reflexão, alimentada por conceitos teóricos e na experiência diária.

Partimos do pressuposto de que a teoria vygotskiana sobre a mediação e interação social para a aprendizagem e desenvolvimento pode ser um caminho teórico para iluminar esses seminários. Essa teoria destaca que os processos internos de desenvolvimento do sujeito estão diretamente ligados ao ambiente em que ele se desenvolve, à comunidade, ao grupo social, às práticas e aos indivíduos com os quais compartilham suas experiências. Dessa maneira, as práticas desenvolvidas pelos alunos com ajuda dos laptops podem ser ponto de partida para que representações mentais possam ser desenvolvidas e que aconteçam operações mentais relacionadas à internalização. Oliveira (2003, p. 34) reforça que “[...] a utilização de marcas externas (signos) vai se transformar em processos internos de mediação; mecanismo esse chamado por Vygotski de processo de internalização".

Assim, a mediação (VYGOTSKI, 2007) é uma ação que ocorre no âmbito social por meio de instrumentos, de objetos, de palavras, de textos, de símbolos, dentre outros elementos. Sendo assim, a mediação pode ser uma estratégia de interação entre sujeito e objeto de conhecimento, e pode ser representada pela tecnologia digital, no caso o laptop, que dessa abordagem pode atuar como potencializador da aprendizagem. A internalização é um processo que se dá como uma reconstrução interna a partir de uma operação externa. (VYGOTSKI, 2007). Assim, o professor precisa realizar intervenções para que as atividades realizadas com a presença do laptop sejam significadas pelo aluno.

A mediação, para ser mais eficaz, precisa ser realizada na zona de desenvolvimento proximal do aluno (VYGOTSKI, 2007), que pode ser identificada pela observação atenta aos movimentos dos mesmos: suas dúvidas, erros e procedimentos, ao realizarem suas tarefas escolares. Assim, o professor pode fazer intervenções que incentivem, provoquem e auxiliem o aluno de forma que eles possam transformar as ações externas realizadas com ajuda dos laptops em movimentos internos de significação e compreensão.

Vygotski (2007) considera a existência de dois níveis de desenvolvimento: o real e o potencial. No primeiro, o indivíduo é capaz de realizar tarefas com independência, e caracteriza-se pelo desenvolvimento já consolidado. No segundo, o indivíduo só é capaz de realizar tarefas com a ajuda do outro, o que denota desenvolvimento. A Zona de desenvolvimento potencial pode ser entendida como distância entre o conhecimento real 
e o potencial; ela pode ser ponto de partida para novas funções psicológicas sejam consolidadas.

Sob esse formato, a estratégia mediadora é o elo entre o aluno e o objeto de conhecimento e carece da ação do professor, ou ainda de outro colega, mas se fundamenta principalmente no papel do professor (MATUÍ, 1995), que pode fomentar que o aluno realize as atividades intermediadas com o laptop de forma significativa, que potencialize seu desenvolvimento cognitivo.

Em geral, o professor foca suas estratégias em apresentar, explicar, exemplificar o conteúdo. O que estamos propondo, sob a inspiração da teoria vygotskiana, é que ele possa ir além disso, no sentido de trazer o aluno para o processo de interiorizar o que ele realiza de forma externa. Por exemplo, quando ele realiza buscas na internet com auxílio do laptop, a atividade externa pode ser apenas copiar as informações encontradas. O que estamos propondo é que ao intervir o professor possa auxiliar, indicar caminhos, orientar, para que o aluno possa compreender, dar sentido, estabelecer relações entre as informações obtidas e aquilo que ele já sabe, de forma a construir novo conhecimento.

Segundo Oliveira (2000), o aluno precisa ser orientado para que as tarefas escolares possam ser caminho de seu pleno desenvolvimento. Portanto, o desafio das práticas pedagógicas, em especial nesse contexto de inserção digital, é empoderar o aluno para que ele seja capaz de colocar em movimento seus instrumentos internos (psicológicos).

Nesse caminho, Vigneron e Oliveira (2005, p. 138) afirmam que:

É preciso utilizar as novas tecnologias como espaço de produção de conhecimento e não apenas formar consumidores de informação. É necessário alterar a ordem de uma escola de consumo de novas e de velhas tecnologias para uma escola de construtores de conhecimento, de sujeitos autônomos e criadores de significados. É imprescindível formar cidadãos protagonistas e não simplesmente consumidores de obras do outro. Ensinar por meio das tecnologias e estabelecer outros caminhos para relações estabelecidas na escola possibilitam a transformação do aluno em produtor do conhecimento e de cultura.

Assim, ao incentivar a participação ativa do aluno em seu processo de aprender, realizando intervenções mediadoras, atuando na zona de desenvolvimento onde ele se encontra, explorando seu potencial criativo, o professor se transforma em agente 
transformador como propõe a visão sócio interacionista de Vygotski. E dessa maneira os recursos digitais pode se tornar um recurso pedagógico com potencial para sustentar processos de desenvolvimento e aprendizagem.

Importante ressaltar que para atuar desde essa perspectiva os professores carecem redimensionar suas crenças sobre como os alunos aprendem e assim, revisarem suas formas de realizar suas intervenções pedagógicas.

Essas considerações indicam que seminários de reflexão e de estudo com os professores, tendo como base o laptop como mediador da aprendizagem, pode ser um caminho para que os professores possam ir além a seu processo de redimensionar suas práticas no contexto da inserção de laptops. Esse caminho poderá auxiliar na articulação dos laptops às práticas pedagógicas de uma maneira mais inovadora e rica.

Moraes, Laurino e Machado (2013) discorrendo sobre a formação docente para lidar com recursos digitais articulados às práticas pedagógicas inovadoras, recomendam que essa precisa ser pautada pela experimentação desses professores, como sujeitos que, no seu fazer vão construindo conhecimento sobre a ressignificação desse fazer. As autoras entendem que mudanças nessa prática surgirão como fruto de trocas de saberes com seus pares, como resultado de estudos e reflexão continuados, pautados na vivência e na experiência do professor em seu cotidiano escolar. Analogamente a essas ideias, Soares e Brustolin, (2011) inferem que a inserção digital pode desencadear mudanças como resultado da convivência, da discussão e da reflexão sobre as práticas pedagógicas, considerando as possibilidades que surgem, a partir da interação com os recursos digitais disponíveis. As autoras ainda colocam em relevo que essas mudanças precisam ser apoiadas por fluxos de interação e de cooperação de forma recorrente.

\section{Considerações finais}

São inúmeras as possibilidades de pensar a escola e o seu fazer cotidiano, e múltiplos têm sido os estudos tendo a escolarização como objeto de estudo. Apesar de ter havido um crescimento expressivo de reflexões sobre a materialidade escolar e das práticas pedagógicas relacionadas a ela, continua sendo um grande desafio estudar as políticas e os discursos sobre a introdução das tecnologias digitais na educação, as propostas teórico metodológicas e os processos de formação inicial e continuada dos professores para o uso dessa materialidade. 
O presente texto pretendeu contribuir com essa discussão na perspectiva de como as tecnologias digitais estão sendo entendidas e apropriadas pelos sujeitos no interior da sala de aula. Bem como, no tensionamento dos limites e potencialidades das práticas pedagógicas, e ainda a prospectiva e os desafios futuros dos professores no cotidiano escolar.

Desse modo, entende-se que a compreensão dos limites e desafios dos sujeitos escolares, precisa se concentrar no desenvolvimento de práticas que extrapolem a dimensão meramente operacional das tecnologias digitais educacionais. Diante dessas reflexões e considerações, evidencia-se a demanda por seminários entendidos como encontros sistemáticos dos professores, em seu contexto de atuação, para juntos construírem alternativas compatíveis com seus saberes, suas percepções e compreensões. Trata-se de ir além de proposições de capacitação ou cursos onde o foco é a transmissão de informações, mas, de momentos de profunda reflexão sobre a prática, o pensando o fazer, em movimentos de tomada de consciência e de redimensionamento de uma prática que carece ser transformada em novos modos de ensinar.

\section{REFERENCIAS}

BARBIER, R. Escuta sensível na formação de profissionais de saúde. Conferência na Escola Superior de Ciências da Saúde - FEPECS-SES-GDF. Brasília, 2002. Disponível em: 〈http://www.barbier-rd.nom.fr/ESCUTASENSIVEL.PDF〉. Acesso em: 08 maio 2017.

BRASIL. Resolução FNDE/CD no 17 de junho de 2010. Estabelece normas e diretrizes para que os Municípios, Estados e o Distrito Federal se habilitem ao Programa Um Computador por Aluno - PROUCA. Disponível em: http://www.fnde.gov.br/programas/programa-nacional-de-tecnologia-educacionalproinfo/proinfo-projeto-um-computador-por-aluno-uca. Acesso em: 08 maio 2017.

CHARTIER, R. A História cultural: entre práticas e representações. São Paulo: Difel, 1990.

FAGUNDES, L. C.: VALENTINI, C. B.; SOARES, E. M. S; Linguagem, educação e recursos midiáticos: quem mexeu na minha escola? In: Ética, educação e tecnologia: pensamento em alternativas para os desafios da educação na atualidade. Pescador, C. Soares, E. M. S., Nodari, P. C. (Org.). Curitiba: Editora CRV, 2010.

LOPES, D. Q.; VALENTINI, C. B.. Mídias Locativas e Realidade Mixada: a produção de sentidos sobre o digital-virtual a partir da cartografia com suporte das tecnologias digitais. Educação Unisinos, v. 16, p. 205-214, 2012. 
MASCHIO, E. C. F.; MARTINS, O. B.. As tecnologias digitais na escola e a formação docente: representações, apropriações e práticas. Actualidades Investigativas em Educación, v. 14, p. 01-21, 2014.

MATUI, J. Construtivismo: teoria construtivista sócio-histórica aplicada ao ensino. SP: Moderna, 1995.

MILL, D.. Escritos sobre educação: desafios e possibilidades para ensinar e aprender com as tecnologias emergentes. São Paulo: Paulus, 2013.

MORAES, M. C.; LAURINO, D. P.; MACHADO, C. C.. Práticas docentes atualizadas na ecologia digital. Renote, Revista Novas Tecnologias na Educação. v.11, n. 3, p. 110, 2013. Disponível em http://seer.ufrgs.br/index.php/renote/article/view/44448/28166. Acesso em: 15 maio 2017.

MORAES R.; GALIAZZI, M. C. Análise textual discursiva. Ijuí: Ed. Unijuí, 2007.

NETO, O. C.; MOREIRA, M. R.; SUCENA, L. F. M. Grupos Focais e Pesquisa Social Qualitativa: o debate orientado como técnica de investigação. Trabalho apresentado no XIII Encontro da Associação Brasileira de Estudos Populacionais, MG, 2002.

MOSCOVICI, S.. A representação social da psicanálise. Tradução de Cabral. Rio de Janeiro: Zahar, 1978.

SOARES, E. M. S.; BRUSTOLIN, R. K. Formação humana dos educadores na era digital: convivência e conversações em grupos focais. CONGRESSO

INTERNACIONAL DE EDUCAÇÃO: Profissão docente há futuro para esse ofício? VII. Anais. São Leopoldo, RS, 2011.

VALENTINI, C. B.; PESCADOR, C.; SOARES, E. M. do S.. O laptop educacional na escola pública: letramento digital e possibilidades de transformação das práticas pedagógicas. Educação (Santa Maria. Online), v. 38, p. 151-164, 2013.

OLIVEIRA, M. K. et al . Piaget-Vygotsky: Novas contribuições para o debate. 6. ed. São Paulo: Editora Ática, 2000.

VIGNERON, J.; OLIVEIRA, V. B. (org.) Sala de aula e tecnologias. São Bernardo do Campo: UMESP, 2005.

VYGOTSKY, L. S. A formação social da mente: o desenvolvimento dos processos psicológicos superiores. 7. ed. São Paulo: Martins Fontes, 2007.

ZABALA, A.. A prática educativa: como ensinar. Porto Alegre: Editora Artes Médicas Sul Ltda. 1998. 


\section{Como referenciar este artigo}

SOARES, Eliana Maria do Sacramento.; MASCHIO, Elaine Cátia Falcade. Práticas, representações e mediação: o uso dos laptops educacionais e as intervenções docentes no processo de aprendizagem da educação básica. Revista Ibero-Americana de Estudos em Educação, Araraquara, v. 12, n. esp. 2, p. 1372-1390, ago./2017. Disponível em: <http://dx.doi.org/10.21723/riaee.v12.n.esp.2.10075>. E-ISSN: 19825587.

Submetido em: 07/07/2017

Aprovação final em: 18/08/2017 